\title{
Evaluación in vitro del efecto antibacteriano del Croton lechleri sobre cultivos de Streptococcus mutans (ATCC 25175).
}

\section{In vitro evaluation of the antibacterial effect of Croton lechleri in Streptococcus mutans crops (ATCC 25175).}

\author{
César Cayo $^{1}$, Rodolfo Barrera ${ }^{2}$
}

http://dx.doi.org/10.21503/CienciayDesarrollo.2014.v17i1.01

\section{RESUMEN}

La presente investigación tuvo como objetivo evaluar el efecto antibacteriano in vitro del Croton lechleri en el crecimiento de cepas del Streptococcus mutans (ATCC 25175). Este trabajo responde a un diseño experimental in vitro, de tipo aplicada, transversal, prospectivo, y de nivel descriptivo. Para la cual se usaron concentraciones diferentes del Croton lechleri y se midieron los halos de inhibición formados alrededor de los discos embebidos con cada una de las concentraciones sobre las cepas del Streptococcus mutans (ATCC 25175). Como resultado se obtuvo que las concentraciones de 100\% y $75 \%$ del Croton lechleri mostraron efecto inhibitorio positivo en los cultivos de cepas del Streptococcus mutans (ATCC 25175), mientras que la concentración del $40 \%$ no tuvo efecto inhibitorio en los cultivos de cepas del Streptococcus mutans (ATCC 25175). En conclusión existe un efecto antibacteriano de la Sangre de grado (Croton lechleri) inhibitorio positivo a las en cultivos de Streptococcus mutans (ATCC 25175).

Palabras clave: Croton lechleri, in vitro, Agar Müller hinton, Streptococcus mutans (ATCC 25175)

\section{ABSTRACT}

This research aimed to evaluate the antibacterial effect in vitro of Croton lechleri in Streptococcus mutans strains growth (ATCC 25175). This work responds to an in vitro experimental, applied, transversal, prospective and descriptive design in which were used different concentrations of Croton lechleri and were measured the inhibition halos formed around embedded discs with each of the concentrations of Streptococcus mutans strains (ATCC 25175). As a result, it was found that concentrations of $100 \%$ and 75\% of Croton lechleri showed the positive inhibitory effect in Streptococcus mutans strain culture (ATCC 25175), whereas the concentration of $40 \%$ had not inhibitory effect in Streptococcus mutans strain culture (ATCC 25175). In conclusion, there is a positive antibacterial inhibitory effect of Sangre de Grado (Croton lechleri) instead of Streptococcus mutans culture (ATCC 25175).

Key words: Croton lechleri, in vitro, Müller Hinton agar, Streptococcus mutans (ATCC 25175).

\footnotetext{
Docente de Embriología e Histología de EAP de Estomatología Filial Huacho. E-mail: cesarcayorojas@gmail.com

2 Bachiller de Estomatología de la Facultad de Medicina Humana y Ciencias de la Salud de la UAP sede - Huacho. E-mail: aaron_diegob@hotmail.com
} 


\section{INTRODUCCIÓN}

Dentro de los antecedentes relacionados al trabajo de investigación, se tomó en consideración los trabajos realizados por diferentes autores nacionales en los últimos diez años.

Los niños peruanos entre los 3 y 12 años de edad tienen la tasa más alta de incidencia de caries en comparación con otros países de América Latina, debido a una mala higiene bucal y otros factores educacionales, advirtieron voceros del Ministerio de Salud. (1)

Lazo Chambilla, en el año 2007 en el Perú, realizó un estudio del extracto de Croton lechleri para la disminución de la bacteria generadora de gingivitis. Los resultados mostraron que los pacientes que fueron sometidas a tratamiento con el Croton lechleri presentaron una disminución en el edema a partir de las 24 horas de iniciado el tratamiento, lográndose la recuperación de un $57,3 \%$ de la muestra a los treinta días. (2)

Cosco R. Dany, en el año 2010 en el Perú, hizo un estudio dela actividad inhibitoria del crecimiento de Streptococcus mutans y de flora mixta salival por acción de un aceite esencial. Cuyos resultados se determinaron la sensibilidad de bacterias frente a un aceite esencial, presentando halos de inhibición de mayor diámetro la cepa patrón Streptococcus mutans ATCC 25175 . (3)

Moromi N. Hilda et al, en el 2009 en el Perú, realizó la investigación bibliográfica a partir de tesis de grado y artículos publicados en la Revista Científica, Odontología Sanmarquina. Las evidencias analizadas comprenden que los halos de las sustancia naturales frisan entre los $10-20$ mm, (y en el caso de Croton lechleri llega a 30 $\mathrm{mm}) .(4)$

Castro Luna, en el año 2008 en el Perú, realizó el estudio in vitro del efecto antibacteriano de un aceite, frente a Streptococcus mutans, utilizando concentraciones de 100,50 y 10 por ciento concluyendo este estudio, que el aceite relativamente presenta actividad antibacteriana significativa frente a Streptococcus mutans. (5)

Por lo tanto la importancia de nuestro trabajo radica en que los individuos puedan tratar y controlar y prevenir de forma económica la proliferación anormal de Streptococcus mutans, siendo este el microorganismo más importante en el inicio de la caries.

Es por estas razones que nos planteamos: ¿Cuál es el nivel de eficacia antibacteriana in vitro del Croton lechleri (sangre de grado) en cultivos de Streptococcus Mutans (ATCC 25175)?

La hipótesis principal planteada es: Si El Croton lechleri (sangre de grado) presentaría un alto nivel de eficacia antibacteriana in vitro en relación al cultivo de Streptococcus Mutans (ATCC 25175).

Las hipótesis derivadas son tres:

1) Existiría actividad bacteriana de tipo sensible del Croton lechleri (sangre de grado) al 100\%, en la inhibición del crecimiento de cepas de Streptococcus mutans in vitro.

2) Existiría actividad bacteriana de tipo sensible del Croton lechleri (sangre de grado) al $75 \%$, en la inhibición del crecimiento de cepas de Streptococcus mutans in vitro.

3) Existiría actividad bacteriana de tipo sensible del Croton lechleri (sangre de grado) al $40 \%$, en la inhibición del crecimiento de cepas de Streptococcus mutans in vitro.

Como objetivo principal se planteó: Evaluar el efecto antibacteriano in vitro del Croton lechleri en el crecimiento de cepas del Streptococcus mutans (ATCC 25175), a través de tres objetivos específicos: 
1) Evaluar el efecto antibacteriano in vitro del Croton lechleri al $100 \%$ en el crecimiento de cepas del Streptococcus mutans (ATCC 25175). 2) Evaluar el efecto antibacteriano in vitro del Croton lechleri al 75\% en el crecimiento de cepas del Streptococcus mutans (ATCC 25175). 3) Evaluar el efecto antibacteriano in vitro del Croton lechleri al $40 \%$ en el crecimiento de cepas del Streptococcus mutans (ATCC 25175).

Las limitaciones presentadas durante el desarrollo del trabajo de investigación fueron: parte la variabilidad del Croton lechleri (sangre de grado) en su composición, y acción como consecuencia de variaciones en la flora de la región donde es producido. Al respecto existen investigaciones como la del Dr. Deepika Guptaa, en la cual describe la botánica, química y usos terapéuticos del Croton lechleri (sangre de grado).

\section{MATERIALES Y MÉTODOS}

El estudio se desarrolló en la ciudad de Huacho durante el mes de diciembre del 2013; la población muestra estuvo conformada por 30 sembrados Streptococcus mutans de placas contenidas de Agar Müller hinton. Los cuales fueron evaluados luego de 42 horas incubadas en la estufa en un ambiente anaerobio, para luego ser medidas con un calibrador o pie de rey y una regla milimetrada estándar.

El cultivo de las cepas se realizó en el laboratorio de microbiología de la Universidad Alas Peruanas - Filial Huacho, por el investigador, bajo la supervisión de una microbióloga. Antes de realizar el cultivo de las cepas, estas se reactivaron, debido a que se encontraban a $-80^{\circ} \mathrm{C}$, para lo cual se sometió a dos pasos de reactivación a las 24 y 48 horas antes del experimento y fueron colocadas a $37^{\circ} \mathrm{C}$.
Posteriormente se realizó el sembrado selectivo, mediante la técnica del hisopado sobre los medios de cultivo respectivos. El Agar Müller - Hinton como el mejor para pruebas de susceptibilidad de rutina de bacterias por las siguientes razones: 1) Reproducibilidad aceptable lote a lote para ensayos de susceptibilidad.

2) Es bajo en inhibidores de sulfonamida, trimetoprim, y tetraciclina.

3) Crecimiento satisfactorio para la mayoría de los patógenos no fastidiosos.

En el manejo del experimento se consideraron dos variables de estudio: una variable independiente, constituida por el efecto antibacteriano in vitro del Croton lechleri (sangre de grado), y una dependiente constituida por la inhibición de crecimiento de cepas del Streptococcus mutans (ATCC 25175).

Luego del sembrado se rotuló con los números respectivos, y finalmente se llevó a la incubadora en un ambiente de $37^{\circ} \mathrm{C}$ en ausencia de oxígeno (idóneo para el crecimiento de los microorganismos).

El microorganismo creció en la superficie de la placa, pero alrededor de los discos se formaron unos halos de inhibición más o menos grandes, dependiendo de la mayor o menor sensibilidad de la bacteria a cada concentración. Se midió el diámetro del halo (expresado en milímetros), se llevó a las tablas y se correlacionaran los diámetros de sensibilidad. $(32)=6$

La correlación diámetro/CIM no se efectúa en términos cuantitativos, porque la técnica no es lo suficientemente exacta como para permitir cuantificar con precisión. $(32)=6$

Se utilizó el programa SPSS para procesar los resultados utilizando métodos analíticos, descriptivos y estadísticos. 


\section{RESULTADOS}

Tabla 1. Estadísticas descriptivas

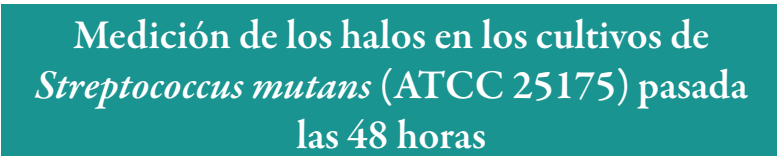

$\begin{array}{cccc}\mathrm{N}^{\circ} \text { de } & 100 \% & 75 \% & 40 \%\end{array}$

$\begin{array}{cccc}\# 1 & 1,5 & 1,1 & 0,1 \\ \# 2 & 1,4 & 0,8 & 0,2 \\ \# 3 & 1,4 & 0,8 & 0 \\ \# 4 & 1,3 & 0,9 & 0,1\end{array}$

$$
\# 5
$$

$\begin{array}{llll}\# 5 & 1,6 & 1,0 & 0\end{array}$

$\begin{array}{llll}\# 6 & 1,7 & 1,1 & 0,4\end{array}$

$\begin{array}{llll}\# 7 & 1,4 & 1,0 & 0,3\end{array}$

$\begin{array}{llll}\# 8 & 1,5 & 1,0 & 0 \\ \# 9 & 1,6 & 1,0 & 0,1\end{array}$

$\begin{array}{cccc}\# 10 & 1,6 & 1,0 & 0,2 \\ \# 11 & 1,4 & 0,9 & 0 \\ \# 12 & 1,5 & 0,8 & 0,2\end{array}$

$\begin{array}{llll}\# 12 & 1,5 & 0,8 & 0,2 \\ \# 13 & 1,5 & 1,0 & 0,1 \\ \# 14 & 1,5 & 0,8 & 0,2\end{array}$

$\begin{array}{cccc}\# 15 & 1,7 & 0,8 & 0,1 \\ \# 16 & 1,6 & 0,8 & 0,1 \\ \# 17 & 1,6 & 0,9 & 0,4 \\ \# 18 & 1,5 & 1 & 0,3\end{array}$

\begin{tabular}{cccc}
$\# 18$ & 1,5 & 1 & 0,3 \\
$\# 19$ & 1,8 & 0,8 & 0 \\
$\# 20$ & 1,7 & 0,9 & 0,2 \\
$\# 21$ & 1,6 & 1,1 & 0,1 \\
$\# 22$ & 1,5 & 1,0 & 0,3 \\
$\# 23$ & 1,5 & 0,9 & 0,3 \\
$\# 24$ & 1,5 & 0,9 & 0 \\
$\# 25$ & 1,7 & 0,8 & 0,4 \\
$\# 26$ & 1,6 & 1,1 & 0,3 \\
$\# 27$ & 1,6 & 1,0 & 0,1 \\
$\# 28$ & 1,3 & 0,9 & 0,1 \\
$\# 29$ & 1,5 & 0,8 & 0,1 \\
$\# 30$ & 1,5 & 0,9 & 0,3 \\
\hline
\end{tabular}

Gráfico 2. Actividad inhibitoria in vitro
sobre cepas de Streptococcus mutans según la
concentración de la sangre de grado "Croton
lecbleri".

Gráfico 2. Actividad inhibitoria in vitro
sobre cepas de Streptococcus mutans según la
concentración de la sangre de grado "Croton
lecbleri".
Gráfico 2. Actividad inhibitoria in vitro
sobre cepas de Streptococcus mutans según la
concentración de la sangre de grado "Croton
lechleri”. lechleri".

Tabla 2. Estadísticas descriptivas

\begin{tabular}{ccc|} 
CONCENTRACIONES DE SANGRE & \\
DE GRADO \\
\hline $100 \%$ & $75 \%$ & $40 \%$ \\
\hline moda & moda & moda \\
\hline 1,5 & 0,8 & 0,1 \\
\hline
\end{tabular}

\begin{tabular}{ccc} 
mediana & mediana & mediana \\
\hline 1,5 & 0,9 & 0,1 \\
\hline
\end{tabular}

\begin{tabular}{ccc} 
media & media & media \\
1,5 & 0,9 & nulo \\
\hline
\end{tabular}

\begin{tabular}{ccc} 
rango & rango & rango \\
0,5 & 0,3 & 0,3 \\
\hline
\end{tabular}

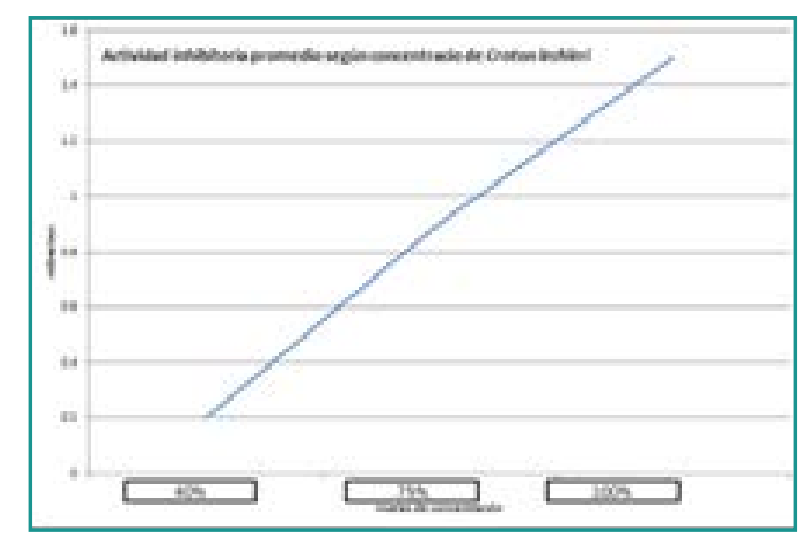

Gráfico 1. Rango promedio de los halos de las concentraciones de sangre de grado (Croton lechleri).

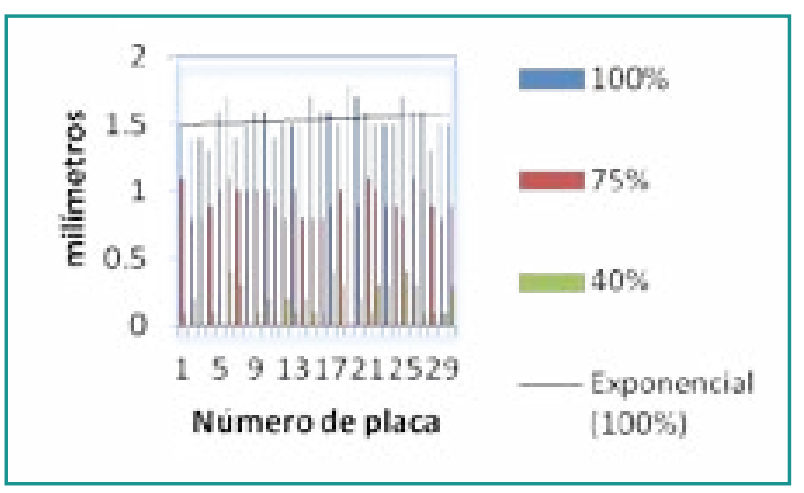
lechleri. 


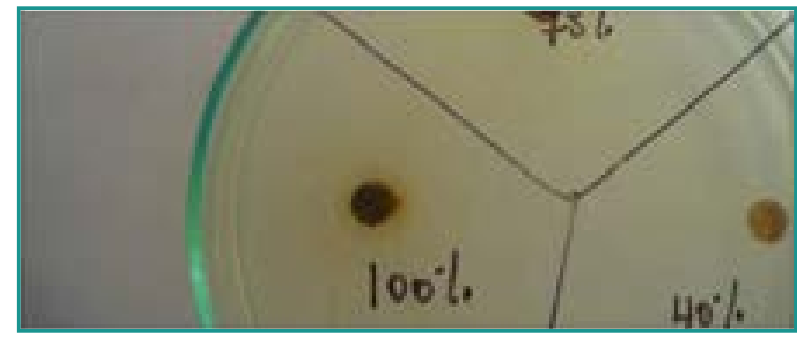

Figura 1. Diferentes halos de inhibición (a).

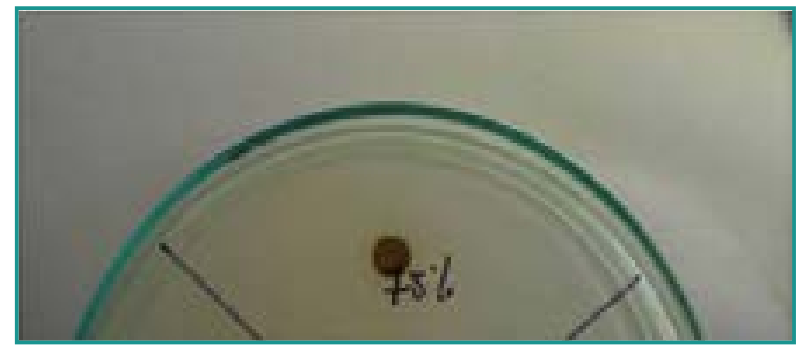

Figura 2. Diferentes halos de inhibición (b).

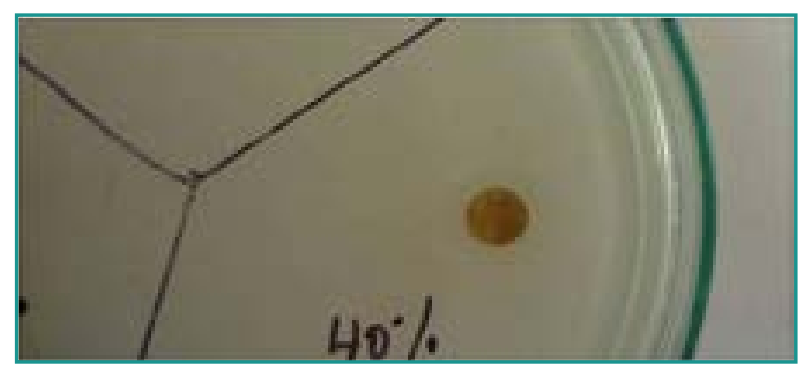

Figura 3. Diferentes halos de inhibición (c).

\section{DISCUSIÓN}

En la presente investigación se buscó determinar si la sangre de grado (Croton lechleri) ejercía efecto inhibitorio sobre cultivos de Streptococcus mutans (ATCC 25175), quedando demostrado la existencia de un efecto de inhibición del desarrollo bacteriano con la sangre de grado (Croton lechleri), según los resultados obtenidos; además se encontró diferencias significativas con respecto al tamaño del halo de inhibición en las distintas concentraciones utilizadas.

En el gráfico $\mathrm{N}^{\circ} 1$, se ilustra las medias de los halos de inhibición expuestas y agrupadas en las tres distintas concentraciones de la sangre de grado (Croton lechleri), observándose que las medias de los halos de inhibición formados para las concentraciones del 100\% 75\% y 40\% muestran diferencias estadísticamente significativas entre ellas.

En el gráfico $\mathrm{N}^{\circ} 2$, se evidencia la actividad inhibitoria in vitro sobre cepas de (Streptococcus mutans) según la concentración de la sangre de grado (Croton lechleri). Identificándose la actividad antibacteriana de tipo sensible en concentraciones del $100 \%$ y $75 \%$, evidenciando que la concentración al $40 \%$ no es sensible ante crecimiento bacteriano in vitro.

Los resultados demostraron que existen diferencias significativas con respecto al tamaño de los halos de inhibición formados ante las diferentes concentraciones de la sangre de grado (Croton lechleri).

Con el presente estudio se determinó la sensibilidad de Streptococcus mutans (ATCC 25175). Frente a la sangre de grado (Croton lechleri), presentando halos de inhibición de mayor diámetro en concentración del $100 \%$. Mientras que los halos de inhibición de menor diámetro fueron con la concentración del $40 \%$.

Lazo Chambilla, en el año 2007 (2), demostró la capacidad de disminuir con el extracto de la sangre de grado (Croton lechleri) mediante topicaciones, una cantidad de bacterias de la cavidad bucal, lo cual concuerda con nuestro trabajo, la cual únicamente se estudió el efecto inhibitorio frente cultivos de Streptococcus mutans (ATCC 25175), a diferentes concentraciones.

En su estudio Moromi N. Hilda et al, (4) demostró, en estudios in vitro e in vivo el efecto inhibitorio y antibacteriano de diferentes extractos, tanto sus principios naturales como antibacterianos orales. En los análisis referente al tamaño del diámetro del halo se concluye que, los halos de las sustancias naturales frisan entre los 10 - $20 \mathrm{~mm}$, nuestro estudio coincide en el efecto inhibitorio del Streptococcus mutans a diferentes 
concentraciones demostrándose la evidente efectividad antibacteriana.

\section{CONCLUSIONES}

Para analizar los resultados se empleó el programa SPSS, lo cual arrojo que comparar la sangre de grado a diferentes concentraciones, reconocemos que cada uno tiene diferentes comportamientos con respecto a la inhibición de los halos de crecimiento del Streptococcus mutans, por tanto: La cepa de Streptococcus mutans ATCC®25175TM fue más sensible a la sangre de grado "Croton lechleri", con una medida de $1.8 \mathrm{~mm}$ de diámetro en sus halos de inhibición para la concentración al $100 \%$.

La cepa de Streptococcus mutans ATCC®25175TM fue sensible a la sangre de grado (Croton lechleri), con una medida de $1,1 \mathrm{~mm}$ de diámetro en sus halos de inhibición para la concentración al 75\%.

La cepa de Streptococcus mutans ATCC $® 25175 T M$ no fue sensible a la sangre de grado "Croton lechleri", con una media de $0, \mathrm{~mm}$ (nula) de diámetro en sus halos de inhibición para la concentración al $40 \%$.

\section{AGRADECIMIENTOS}

$\mathrm{Al}$ director de la EAP de Estomatología CD. Javier Ramos de los Ríos por brindar las facilidades administrativas para el desarrollo de esta investigación.

\section{REFERENCIAS BIBLIOGRÁFICAS}

1. Ministerio de Salud, estadísticas en salud dental en América Latina y sus causas [base de datos en línea]. Perú: Editorial Ministerio de Salud del Perú; 17 de
Marzo 2011 [ 15 de Noviembre 2013] .URL disponible en: http://www.minsa.gob.pe/

2. Lazo Chambilla, Extracto de Croton lechleri y de Pelargonium robertianum $\mathrm{L}$ en el tratamiento de la gingivitis. [Tesis]. Lima-Perú: Universidad San Martin de Porres; 2007.

3. Cosco R. Dany. Azaña E, Isaac Actividad inhibitoria del crecimiento de Streptococcus mutans y de flora mixta salival por acción de aceite esencial. [Tesis]. Lima-Perú: Universidad Nacional Mayor De San Marcos; 2010.

4. Moromi Hilda et al, Antibacterianos naturales orales: Estudios en la facultad de Odontología de la Universidad Nacional Mayor De San Marcos. Revista Científica odontología Sanmarquina EneroJunio 2009; vol. 12 ( $\mathrm{N}^{\circ} 1$ ): pág. 25-28

5. Castro L, Américo. Composición química del aceite esencial de las hojas de Erythroxylumnovogranatense (Morris) "coca", actividad antioxidante y determinación antibacteriana frente a Streptococcus mutans- [Tesis]. Lima- Perú; 2008.

E-mail:cesarcayorojas@gmail.com 